\title{
AC 2010-2219: FACULTY PRACTICES IN EFFECTIVE ONLINE STUDENT ASSESSMENT IN ENGINEERING AND TECHNOLOGY
}

Ali Mehrabian, University of Central Florida

Walter Buchanan, Texas A\&M University

Alireza Rahrooh, University of Central Florida

Tarig Ali, University of Central Florida

Saeid Moslehpour, University of Hartford 


\title{
Faculty Practices in Effective Online Student Assessment in Engineering and Technology
}

\begin{abstract}
Distance learning is recognized in the engineering and technology-related education profession as an attractive method of instructional delivery. The asynchronous and economical advantages of distance education and learning make offering and taking them very popular. The fast pace availability of the technology and its rapidly changing environment compel the profession to constantly evaluate, address, re-evaluate and re-engineer some of the assessment-related issues.

In this article, we discuss some aspects of online performance assessment in distance learning environments in engineering and technology. The article is built on the foundation laid by many previous studies and articles by the authors and others. It encompasses discussions on effective techniques on the use of technology for online student performance assessment. We rely on our own many years of online teaching as an experiential instrument in the former parts of this study while we use statistical analysis in the later part of the paper. The data used are collected from recent sample courses in engineering and technology taught by the authors and their colleagues. We conclude that the currently available automated robust and effective online assessment tools are significant in pedagogical assessment in engineering and technology. The results are confirmed through our discussions with the colleagues having similar experience at some other institutions of higher education. We plan to expand our database and revalidate our study through collaborative data-sharing efforts with our colleagues across the States in the near future.
\end{abstract}

\section{Introduction}

"Distance learning” and interchangeably used in this article "distance education” are commonly referred to as a field of education that investigates and examines pedagogical technologies and the design of advanced instructional systems used to deliver education remotely to students who are not physically present in the classroom. Present technology and the accessibility of the internet have made distance learning much more viable, and it has evolved from traditional ways to robust, more efficient, and more convenient for students and faculties. Online teaching and learning is progressively regarded as a means of increasing flexibility and robustness of delivery to provide for greater student access to, and control over, their learning whether they are studying on-campus or in distance mode, or offshore ${ }^{1,2,3}$.

Current technologies allow faculties and students to communicate asynchronously, at times and locations of their own choosing, by exchanging printed and or electronic information. New technology, such as Blackboard ${ }^{\mathrm{TM}}$, provides a more efficient and robust management system for remote classrooms. With this new trend in distance learning and education, in recent years distance education and learning have emerged as a popular method of instructional delivery in engineering and technology-related fields. Many faculties of engineering and technology may find themselves teaching online classes or thinking about teaching one. In this process, crafting online assessment techniques and rubrics without sacrificing the educational quality and security is a crucial issue to the faculty. This process can be quite challenging at times particularly for 
the faculty that do not have any prior experience with teaching online courses. Psychological setbacks and barriers among undergraduate engineering students add another concern for the faculty, i.e., students may have fears of losing partial credit in an online multiple-choice assessment. The asynchronous and economical advantages of distance education and learning that make offering and taking them very popular force the engineering education profession to re-examine, re-organize, and re-engineer some of the assessment-related issues that otherwise don’t exist.

The use of online-based, "honest, open book, open mind" approach is being recognized in the literature as a potential method of assessment for distance courses in the faculties of engineering, science, and technology ${ }^{1,3}$. Faculty may have to develop new methodologies, and structure or restructure their course differently to accommodate and facilitate the effectiveness of online assessment methods. Some very recent studies documented the practicality and effectiveness of distance learning methodologies ${ }^{3}$. Results from an early study of the desirability and feasibility of using distance learning indicated that this teaching and methodology has a useful role in distance learning ${ }^{4}$. The case for employing project-based learning methods as opposed to more traditional teaching methods, where the learning path follows a carefully predetermined structure, has been argued elsewhere ${ }^{3}$.

In this discussion, the authors discuss their enduring practices and efforts with crafting online assessment methodologies for the distance learning courses in engineering and technology. We touch on issues of assessment, security, inclusion, etc. We use some accurate but crude empirical data and evaluation methodologies to draw our conclusions. The sample data used are collected by the authors from more recent sample courses that have been taught by the authors over the last five years. This facilitates the evaluation of the latest challenges, development of new methodologies, and monitoring the current trends. For inclusiveness reasons, we use the words "learner" and "student" interchangeably in this article.

\section{Faculty Concerns}

Learning is seen as essentially a social process, requiring communication among learner, teacher and others. This social process cannot effectively be replaced by technology, although technology may facilitate it ${ }^{5}$. While faculties are concerned with students' learning outcomes and assessment, we observe that students are often concerned with their grades. Rightly so, but in some instances, students may take this too far and transform the reputation of a course from a learning-centered course to a grading-centered focus. In this case, the learning effectiveness is adversely affected.

Recognizing that grades can be used as an important assessment tools in many instances, it is essential to ensure the impartiality of the assessments and thus increasing the effectiveness of this important assessment tool. This is particularly applicable in an online assessment environment in which granting partial credit is neither practical nor manageable. How can a faculty ensure that a student's knowledge about the subject matter is measured by an online assessment if the entire knowledge of the student about the subject matter can not be measured? Most online assessments consist of either multiple choice, true/false, or short answer type of questions. In some online assessments the combinations of the questions and their different 
types are used. In each case, there are variations in the responses. However, the inability of granting partial credit in an online assessment environment may indicate false assessment measures of the students' progress in the course. Nevertheless, we believe that the following issues and concerns may challenge the faculty and are more common in performance assessment for the engineering and technology-related courses:

1. Assessment Security: In an online “open book, open notes, open mind” assessment environment where there is no live proctor or visual monitoring, the assessments shall be crafted accordingly to prevent or reduce the likelihood of plagiarism or illegal use of the available materials. Several such cases are reported by Colwell and Jenks in $2005^{6}$. This concern affects the student's performance assessment accuracy due to the difficulty of controlling the security of online assessment environment against plagiarism. One remedial action that we found effective is that the student should be tested more on the concepts rather than the material that can be easily plagiarized. While this may work well for some engineering courses, it is not an easily duplicable task for some design courses that heavily relied on calculations. Another method for reducing the likelihood of plagiarism, is to use a contract similar of that presented in Colwell and Jenks ${ }^{6}$. Depending on the course under consideration, we also use random question/problem generators in WebCT ${ }^{\mathrm{TM}}$ and Blackboard ${ }^{\mathrm{TM}}$. One may feel that with the current available technologies, this is one of the trade-offs of distance learning. However, like any other assessment environment, there should be less concern about the assessment security if the students are honest about their learning. Honesty is the best policy to enforce that fairly eliminates this issue.

2. Interactivity: For those involved in designing online environments special attention must be afforded to interactivity. Online tasks should involve students actively engaging with tools and resources they will potentially use in their later employment.

Some faculty may feel that they should be available during the assessment period. Some student suggests to us informally that they feel that they perform better if taking "live" assessments in presence of a faculty or teaching assistant (TA) as opposed to "online” assessments. If that is the case, the availability of the faculty is essential in case students have questions regarding the assessment content and material, or to eliminate any student's psychological set backs. The faculty may desire to inform the students in advance about the assessment availability period and his/her availability. Students can remotely contact the faculty via instant emails, messengers, and even telephones while taking the assessment.

Some studies also suggest that using Java applets, embedded in course web sites, can enhance educational material with animations, applications that are responsive to student choices, and provide interactivity to engage students in active learning ${ }^{7}$. Crisp indicates that the interactivity inherent in these applets allows a student to explore, to make errors, and seek their own solutions. They can all be incorporated into online assessment to allow students to interact with real tools ${ }^{7}$.

3. Equity: Some faculty is concerned with the level of difficulty of questions for different students. They believe that all students taking the same course at the same time shall receive assessments of the same level of difficulty. Faculty may feel that this is just and equitable. 
In an online environment, we propose "guided grouping" of the assessment questions in which we divide the questions according to their level of difficulty. We then use questions at random for the same assessment for the same course. This is applicable to cases in which we use random question generation functions in the online course management systems. Faculty may have to go through a period of "trial and error" phase before they can master this method. It also requires more time and dedication in crafting online assessments for the courses with less available resources for the faculty.

4. “Hands-on” Demonstration of Concept: In hands-on laboratory environments, some faculty would prefer their students demonstrate their understanding of the concept. This is particularly applicable to engineering technology course assessment where hands-on application of the concept is vital to students learning assessment. In such cases, such as a senior design course, we currently have scheduled presentation sessions where students demonstrate the workability of their built devices.

The assessment of hands-on demonstration can become highly subjective. We recommend using the same rubrics by multiple faculties present during the student's presentation.

5. Team-workability Assessment: Group performance and team-workability skills are important tasks for the engineering and technology students to learn while they are still at school. In an online course environment, there should be methods of assessment for students' workability and performance in teams. We assess students' performance in teams by methods described and used by Mehrabian et $\mathrm{al}^{8}$ where they described their experiences for a senior design project course. In this case, students worked remotely in teams. In some case the students (team members) lived as far as 200 miles apart from each other.

6. Ethics: The Engineering Criteria 2000 of the Accreditation Board for Engineering and Technology (ABET) pledge to significantly and rigorously improve the landscape of engineering education in the United States. One outcome of Criteria 2000 is increased attention in the curriculum to the ethical responsibilities of engineers. This is certainly a concern among many faculties including those teaching courses in online learning environments. The focus is to achieve meaningful ethics education for all engineering students, with particular emphasis on competing curriculum models.

Our enduring practice with crafting online assessments was a student-centered approach in the past. By using a "student-centered" approach, we imply relying on students themselves to be at the center of the process. In this approach students are expected to be as truthful and selfdisciplined as possible when taking examinations in an online learning environment. We recently focused more on providing the learners with some documents serving as ethical guidelines for taking online examinations. This is due to our findings that most learners are truthful, but they simply don't have any frame of reference to ethical behavior when taking examinations in an online learning environment. The learners must read the ethical guidelines document and agree to it before they can take an online examination. In "open and honest" online learning and teaching environments they also sign statements confirming that they conform to these guidelines before, during, and after an assessment. In the near future, we plan 
to supply the learners with an online video clip, discussing assessments ethics and citing specific cases of online assessment ethical violations.

\section{Performance Assessment Methodologies}

Online learning systems and the available technology allow faculty to design assessments with different types of questions and settings including, but not limited to multiple choice, true/false, matching, short question, paragraph, and calculations. Another useful mechanism for the faculty is the ability to set up the online learning system to select randomly sets of questions for the same assessment. To use this mechanism effectively, there should be ample questions in the database. The system can be set up as such to allow students to take an assessment during a specific period. We experiment with different assessment periods, from 2 hours up to 48 hours, to accommodate many students that are also full-time working adults. This is particularly applicable in engineering technology courses. Another valuable feature is the ability to set the system as such to allow students to take the same assessment multiple number of times, or only one time. If the faculty desires to assess students on the understanding of the concepts, less accessibility of the students to notes and books is perhaps desirable. To be able to ensure the integrity of online assessments, one issue of concern to faculty is the ability to adjust assessment time in such a way that students won't be able to use their class notes, text book, etc. to answer the online examination questions.

In engineering and technology, many of the examinations include graphic-based questions. The learning systems mentioned above may not be capable yet of allowing faculty to fully design and implement that type of examination questions using available resources. To compensate for this present shortcoming feature, we think graphic-based examination questions can be designed in such a way that students can work on in groups using, for example, the capability of Autodesk ${ }^{\circledR}$ AutoCAD of allowing collaborative design. The contribution and input of every member in a group can be assessed and graded as all activities of given group of students at time stamped. In a course taught by the authors, student groups working different term assignments were assigned discussion boards only accessible by the group members. No one else has access to that discussion environment, but the Faculty. Browsing individual groups' discussion boards can give faculty some indication of the assessment of the performance and contributions of group members. We believe these discussion boards can help providing faculty with some guidelines for preparing online assessments. One may argue that such a method is casual and less formal than traditional methods of assessment and evaluation.

\section{Data and Discussions}

Assessments may viewed by many as measures of learners’ learning success and teaching effectiveness in both live and distance learning courses. In engineering and technology related courses, assessments are routinely used for this purpose. Depending on the course, other methods are also used by many institutions of higher educations.

At many institutions some courses are offered as live and distance, simultaneously. This is to include both live and distance students in the same course, thus providing more educational opportunities while increasing the efficiency of a course delivery system. Among many other 
advantages, this would also reduce and sustain human and material resources. It is intuitive to mention that due to their choice of instructional and delivery mode, distance learners don't usually attend the live lectures. However, live students are not limited to live discussions only, and they do have access to the course material available to them online through the course website. We note that when a course is offered in two different modes of "live" and "distance" simultaneously in the same semester, the "live" students tend to access the course materials available online. This data provided here is presented for the two sections taught by the same professor. We may interpret from this data that "live" students seem to have out-performed their counterparts taking the course at a "distance" only. One may conclude from this data that students who have access to multiple methods of learning are more likely to succeed. This is a work in progress and more information will become available as we complete our assessment of students progress and success in online versus live courses.

The authors and their colleagues offered some same undergraduate courses in different semesters using different modes of instructions of synchronous and asynchronous. Some data presented here are for comparison and assessment of the results. For the purpose of consistency and conclusiveness, we present the data that are related to the six issues raised in the former sections of this paper. The results presented here are confirmed through our discussions with the colleagues having similar experiences at other institutions of higher education. We plan to revalidate our data through collaborative efforts with our colleagues in 2010 and present the results in 2011.

The following data shown in Table 1 is a comparison between the percentage of live and distant students passed the same course taught by the authors offered using distance and live modes of instructions in 2005, 2006, 2007, and 2008. The courses had almost the same number of registered students. There is no observed significant difference between the level of competency of the students taken different sections of the same course. We used the data in which almost all other parameters influencing the students' performance are identical. For brevity, we don't elaborate on those parameters here.

\begin{tabular}{|l|l|c|c|}
\hline Case No. & Course No./Semester & Percentage of Students Passed the Course \\
\cline { 3 - 4 } & & Live section & Distance Section \\
\hline 1 & 1/ Spring 2005 & 90 & 100 \\
\hline 2 & 1/ Spring 2006 & 85 & 95 \\
\hline 3 & 2/ Fall 2005 & 90 & 100 \\
\hline 4 & 2/ Fall 2006 & 90 & 95 \\
\hline 5 & 2/ Fall 2007 & 100 & 100 \\
\hline 6 & 3/ Fall 2005 & 95 & 100 \\
\hline 7 & 3/ Fall 2006 & 95 & 100 \\
\hline 8 & 3/ Fall 2007 & 80 & 100 \\
\hline 9 & 3/ Fall 2008 & 95 & 100 \\
\hline
\end{tabular}

Table 1: Percentage of Live and Distant Students Passed the Course

In eight cases out of the nine cases evaluated here, the percentage of the students passed the distance section of the same course is higher by 5 percent or more than the percentage of the 
students taking the live section of the course. This may or may not attribute to the level of the assessment security, and it doesn’t provide any proof or disproof of plagiarism. Indeed, to reduce the likelihood of plagiarism, we did use a contract similar of that presented in Colwell and Jenks ${ }^{6}$ for distant examinations, something that we did not apply to live assessments. For the same course number and corresponding term, the assessments and their completion time are identical for both live and distance sections. In fact, examinations taken by live students were more interactive than those taken by distance students.

We found no correlations between assessments interactivity and the percentage of students passed the course. There is also no indication on the course size and the percentage of the students passed the course here in this study.

Table 2 below shows the result of the same assessment (exam I - Fall 2008) taken by the same group of students, live and online. The live assessment was taken a week later after the students have taken the online assessment. The two examinations have the same set of questions in three sections: definitions of key terms, short questions, and matching. The live section statistics are as follows: max grade $=97 \%$, min grade $=38 \%$, average $=86.18 \%$ and standard deviation $=12.69$. The online section statistics are as follows: $\max$ grade $=100 \%$, $\min$ grade $=53 \%$, average $=$ $82.52 \%$ and standard deviation $=11.60$. By comparing the performance of this group of students, it appears that the students did better overall in the online examination although it was taken a week before the live one. Again, this may or may not attribute to the level of the examination security as we have no proof or disproof of plagiarism. Indeed, to reduce the likelihood of plagiarism, we rely on a contract discussed previously, something that we did not apply to live examinations.

\begin{tabular}{|c|c|c|c|c|c|}
\hline Student & Live & Online & Student & Live & $\underline{\text { Online }}$ \\
\hline $\mathrm{x} 1$ & 93 & 53 & x18 & 87 & 77 \\
\hline $\mathrm{x} 2$ & 92 & 77 & $\mathrm{x} 19$ & 71 & 70 \\
\hline x3 & 93 & 77 & $\mathrm{x} 20$ & 95 & 93 \\
\hline $\mathrm{x} 4$ & 86 & 90 & $x 21$ & 90 & 87 \\
\hline $\mathrm{x} 5$ & 90 & 90 & $\mathrm{x} 22$ & 72 & 77 \\
\hline$x 6$ & 92 & 100 & $x 23$ & 93 & 67 \\
\hline $\mathrm{x} 7$ & 97 & 72 & $\mathrm{x} 24$ & 93 & 90 \\
\hline$x 8$ & 97 & 82 & $\mathrm{x} 25$ & 93 & 77 \\
\hline x9 & 87 & 98 & $\mathrm{x} 26$ & 38 & 88 \\
\hline $\mathrm{x} 10$ & 86 & 98 & $\mathrm{x} 27$ & 90 & 88 \\
\hline $\mathrm{x} 11$ & 91 & 95 & x28 & 77 & 77 \\
\hline $\mathrm{x} 12$ & 97 & 78 & $\mathrm{x} 29$ & 93 & 62 \\
\hline x13 & 71 & 92 & X30 & 96 & 92 \\
\hline $\mathrm{x} 14$ & 87 & 83 & x31 & 94 & 92 \\
\hline $\mathrm{x} 15$ & 62 & 58 & x32 & 93 & 93 \\
\hline $\mathrm{x} 16$ & 90 & 85 & x33 & 92 & 80 \\
\hline $\mathrm{x} 17$ & 66 & 85 & & & \\
\hline
\end{tabular}

Table 2: Statistics of Exam I, Fall 2008 
Table 3 illustrates the result of online assessment covering the same topics (exam II - Fall 2008) taken by the same group of students, two times: first time the examination was a combination of definition of key terms, short questions, and matching (COMP), and the second time it was all multiple choice examination (MCH). The COMP examination was taken on a Wednesday afternoon and the MCH was taken "a few days later" on Saturday evening. The COMP examination statistics are as follows: $\max$ grade $=98 \%$, min grade $=59 \%$, average $=86.63 \%$, and standard deviation $=10.62$. The $\mathrm{MCH}$ examination statistics are as follows: max grade $=$ $98 \%$, min grade $=53 \%$, average $=80.48 \%$, and standard deviation $=12.36$. By comparing the performance of this group of students on these examinations covering the same topics offered in two formats, it seems the students generally did equally in the two examinations. However, when the individual performance of the students is compared, it seems many students did better on the COMP examination. This does not seem to relate to the examination security. We believe this has a lot to do with personal preference and comfort.

\begin{tabular}{|l|c|c|l|c|c|}
\hline Student & COMP & $\underline{\text { MCH }}$ & $\underline{\text { Student }}$ & $\underline{\text { COMP }}$ & $\underline{\text { MCH }}$ \\
\hline $\mathrm{x} 1$ & 90 & 88 & $\mathrm{x} 18$ & 96 & 53 \\
\hline $\mathrm{x} 2$ & 77 & 77 & $\mathrm{x} 19$ & 83 & 82 \\
\hline $\mathrm{x} 3$ & 93 & 62 & $\mathrm{x} 20$ & 84 & 80 \\
\hline $\mathrm{x} 4$ & 96 & 92 & $\mathrm{x} 21$ & 68 & 97 \\
\hline $\mathrm{x} 5$ & 94 & 92 & $\mathrm{x} 22$ & 87 & 97 \\
\hline $\mathrm{x} 6$ & 93 & 93 & $\mathrm{x} 23$ & 59 & 83 \\
\hline $\mathrm{x} 7$ & 92 & 80 & $\mathrm{x} 24$ & 87 & 60 \\
\hline $\mathrm{x} 8$ & 92 & 80 & $\mathrm{x} 25$ & 95 & 83 \\
\hline $\mathrm{x} 9$ & 88 & 77 & $\mathrm{x} 26$ & 66 & 72 \\
\hline $\mathrm{x} 10$ & 87 & 70 & $\mathrm{x} 27$ & 67 & 75 \\
\hline $\mathrm{x} 11$ & 97 & 87 & $\mathrm{x} 28$ & 84 & 88 \\
\hline $\mathrm{x} 12$ & 90 & 93 & $\mathrm{x} 29$ & 97 & 65 \\
\hline $\mathrm{x} 13$ & 93 & 90 & $\mathrm{x} 30$ & 98 & 70 \\
\hline $\mathrm{x} 14$ & 94 & 98 & $\mathrm{x} 31$ & 86 & 62 \\
\hline $\mathrm{x} 15$ & 94 & 97 & $\mathrm{x} 32$ & 66 & 57 \\
\hline $\mathrm{x} 16$ & 94 & 88 & $\mathrm{x} 33$ & 75 & 85 \\
\hline $\mathrm{x} 17$ & 97 & 83 & & & \\
\hline
\end{tabular}

Table 3: Statistics of Exam II, Fall 2008

\section{Summary and Conclusion}

This discussion encompasses six faculty concerns of security, interactivity, equity, hands-on demonstration of concept, team-workability assessment, and ethics, all related to pedagogical assessment in engineering and technology. We rely on our many years of online teaching as an experiential instrument in the former parts of this study while we use statistical analysis in the later part of the paper. We use some accurate but crude empirical data and evaluation methodologies to draw our conclusions. The data are collected from more recent sample courses offered over the last five years. Some of the results presented here are confirmed through our discussions with the colleagues having similar experiences at other institutions of higher 
education. We plan to expand our database and revalidate our study through collaborative datasharing efforts with our colleagues in the near future.

We conclude and confirm that the assessment information can be used in different ways: to offer faculty information that may allow them to improve learning, to assist with selection decisions for educational options, and to provide accountability at a number of levels. One of the more important use of assessment is to facilitate improvements of learning outcomes. In an online learning environment, technology can provide a more robust and effective learning assessment using automated tools and techniques.

\section{Bibliography}

1. Azad, A., Song, X. (2006). "Internet-based Physical Experiments: Application within A Laboratory Course," American Society for Engineering Education (ASEE) Annual Conference, Chicago, IL.

2. King, B., McCausland, H. and Nunan, T. (2001) “Converting To Online Course And Program Delivery: The University Of South Australia Case Study,” International Review of Research in Open and Distance Learning: 1, 2. http://www.icaap.org/iuicode?149.1.2.7

3. Mehrabian, A., Alvarado, K., and Nahmens, I., (2007). “Application of Technology in Project-based Distance Learning," EISTA 2007, Orlando, FL.

4. Nunan, T. (2000). “Exploring the concept of flexibility,” In V. Jakupec \& J. Garrick, J. (Eds.), Flexible learning, and human resource development (pp. 47-66). London: Routledge.

5. Bates, A.W., \& Poole, G (2003). Effective teaching with technology in higher education : Foundations for success. San Francisco, CA: Jossey-Bass.

6. Colwell, J. L. and Jenks, C.F., (2005). “Student Ethics in Online Courses: Some Case Histories,” ASEE IL/IN Sectional Conference, DeKalb, IL.

7. Crisp, G. (2002). “Using JAVA Applets to Help Make Online Assessment Interactive,” Learning and Teaching Development Unit, The University of Adelaide, Adelaide, South Australia.

8. Mehrabian, A., Buchanan, W., Rahrooh, A. (2008). "Course Transformation from Live/Synchronous to Remote/Asynchronous Using Technology,” Proceedings of INTERTECH-International Conference on Engineering and Technology Education, pp. 68-72. Sao Paulo, Brazil. 